\title{
Avaliação de propriedades relacionadas à penetração de cloretos em concretos produzidos com substituição parcial de cimento por resíduo de beneficiamento de rochas ornamentais
}

\author{
Evaluation of chloride penetration-related \\ properties in concretes produced with \\ partial replacement of cement by ornamental rock waste
}

Fernando Ritiéle Teixeira ${ }^{1}$, Gustavo Bosel Wally ${ }^{2}$, Fábio Costa Magalhães ${ }^{3}$, Félix Krolow Sell Junior ${ }^{1}$, Charlei Marcelo Paliga ${ }^{4}$, Ariela da Silva Torres ${ }^{4}$

\footnotetext{
${ }^{1}$ Universidade Federal de Pelotas, Programa de Pós-Graduação em Ciência e Engenharia de Materiais, Rua Gomes Carneiro, 01, CEP: 96010-610, Pelotas, Rio Grande do Sul, Brasil

${ }^{2}$ Universidade Federal do Rio Grande do Sul, Laboratório de Ensaios e Modelos Estruturais, Avenida Bento Gonçalves, 9500, CEP: 90650-001, Porto Alegre, Rio Grande do Sul, Brasil

${ }^{3}$ Instituto Federal de Educação, Ciência e Tecnologia do Rio Grande do Sul, Campus Rio Grande, Laboratório de Estruturas e Materiais de Construção Civil, Rua Engenheiro Alfredo Huch, 475, CEP: 96201-460, Rio Grande, Rio Grande do Sul, Brasil

${ }^{4}$ Universidade Federal de Pelotas, Faculdade de Arquitetura e Urbanismo, Departamento de Tecnologia da Construção, Rua Benjamin Constant, 1359, CEP: 96010-020, Pelotas, Rio Grande do Sul, Brasil e-mail: fernandoteixeira5400@gmail.com, gustavo.wally@gmail.com, fabiocmagalhaes@gmail.com, felixsell@gmail.com, charlei.paliga@ufpel.edu.br, arielatorres@gmail.com
}

\section{RESUMO}

Recentemente muitas estruturas de concreto armado têm apresentado manifestações patológicas precocemente, tendo sua vida útil reduzida. Dentre essas manifestações, destaca-se a corrosão das armaduras desencadeada, principalmente, pela ação deletéria dos íons cloreto ou do dióxido de carbono. Em busca de alternativas que reduzam a penetração desses agentes no concreto, neste trabalho é avaliada a influência da substituição parcial de cimento Portland pelo resíduo gerado durante o beneficiamento de rochas ornamentais (RBRO). O resíduo utilizado foi caracterizado através de ensaios de massa específica, granulometria a laser, difração de raios X (DRX) e fluorescência de raios X por dispersão de energia (EDX). Foram produzidos concretos com substituição de cimento por RBRO nos teores de $5 \%, 7,5 \%$ e $10 \%$ em relação à massa de cimento, além de um traço referência. Desses concretos foram avaliadas a resistência à compressão, a absorção de água por imersão e por capilaridade e a penetrabilidade de cloretos. Os resultados indicam que a substituição parcial de até 7,5\% de cimento por RBRO conduziu à obtenção de um material que apresenta comportamento similar ao concreto referência em aspectos como resistência mecânica, absorção de água e penetrabilidade de cloretos, proporcionando um uso sustentável a um resíduo que seria descartado no meio ambiente.

Palavras-chave: Resíduo do beneficiamento de rochas ornamentais. Penetração de cloretos. Durabilidade do concreto.

\section{ABSTRACT}

Recently, many reinforced concrete structures have shown early pathological manifestations, reducing their service life. Among these manifestations, it is highlighted the reinforcement corrosion caused by the deleterious action of the chloride ions or carbon dioxide. Searching for alternatives to reduce the chloride penetration in concrete, this paper assesses the influence of the partial replacement of Portland cement by ornamental rock waste (ORW). The waste used was characterized by specific gravity, granulometric distribution, X-ray diffraction (XRD) and energy dispersive X-ray fluorescence (EDX). Concretes were produced with substitution of cement by ORW in the levels of $5 \%, 7.5 \%$ e $10 \%$ by mass of cement. Of these concretes were eval- 
uated the compressive strength, water absorption by immersion and by capillarity, and chloride penetrability. The results show that the partial replacement up to $7.5 \%$ of cement by ORW led to obtaining a material with behavior similar to the reference concrete in aspects such as mechanical strength, water absorption, and chloride penetrability, providing a sustainable use to a waste that would be discarded in the environment.

Keywords: Ornamental rock waste. Chloride penetration. Concrete durability.

\section{INTRODUÇÃO}

O crescente número de estruturas de concreto armado deterioradas prematuramente devido à corrosão das armaduras causada pela ação dos íons cloreto ou do dióxido de carbono, associado aos elevados custos de manutenção e reparo de estruturas corroídas, conduz ao aumento da importância dada aos projetos de durabilidade e às avaliações de vida útil dessas estruturas [1-3]. De modo geral, sabe-se que quanto maior for a dificuldade imposta à penetração de agentes agressivos na estrutura de poros do concreto, mais durável este será. A esse fato somam-se também outros aspectos, como as características químicas da matriz cimentícia e as condições ambientais às quais a estrutura será exposta $[4,5]$.

Além da preocupação com a durabilidade das estruturas de concreto armado, a busca por inovação com foco na sustentabilidade é uma das principais ações em diversos setores da indústria, destacando-se, na construção civil, os esforços voltados à redução do consumo de cimento Portland na mistura do concreto [6, 7]. Isso ocorre porque a indústria do cimento é fonte geradora de elevados teores de $\mathrm{CO}_{2}$, emitindo cerca de 0,94 t de dióxido de carbono a cada tonelada de cimento produzida [8].

Nesse sentido, GARAS et al. [9] afirmam que a utilização de resíduos de beneficiamento de mármore e granito na mistura do concreto se mostra promissora na mitigação de impactos ambientais, no desenvolvimento sustentável da construção civil e no melhoramento de propriedades do concreto. No Brasil, segundo dados da Associação Brasileira da Indústria de Rochas Ornamentais (ABIROCHAS) [10], a produção de rochas durante o ano de 2017 foi de aproximadamente 9,24 Mt, sendo 1,046 Mt destinadas à exportação. Salienta-se que, em volume, $41 \%$ dos blocos de rochas são transformados em rejeitos, gerando cerca de 3,36 Mt de material descartável durante o processamento das rochas ornamentais. Deve-se atentar, entretanto, ao fato de que, diferente de outros materiais comumente utilizados como adição à mistura do concreto, como sílica ativa e cinza volante, por exemplo, o RBRO apresenta estrutura cristalina e inerte, não reagindo quimicamente com outros compostos do cimento e tendo, portanto, atuação física de preenchimento dos poros do concreto, chamada de efeito filler [11].

GHORBANI et al. [12], após avaliarem a substituição de cimento por resíduo do beneficiamento de granito nos teores de 5, 10 e $20 \%$, apontam que o melhor desempenho mecânico à compressão foi obtido quando utilizado $10 \%$ do resíduo, enquanto a menor absorção de água foi verificada na mistura com substituição de $5 \%$. Já o melhor comportamento frente ao ataque de ácidos foi apresentado pelo concreto com $20 \%$ de resíduo. Por sua vez, SOLIMAN [13] investigou os efeitos da utilização do resíduo de beneficiamento de mármore em diversos teores compreendidos entre 2,5 e $20 \%$. O autor relata que a resistência à compressão do concreto aumentou em média $25 \%$ quando utilizadas substituições de até $5 \%$. Substituições acima deste teor, porém, foram responsáveis pela redução da resistência à compressão em aproximadamente $26 \%$. Além disso, SOLIMAN [13] destaca que a substituição de cimento por resíduo de beneficiamento de mármore em teores entre 5 e $10 \%$ reduz as emissões de $\mathrm{CO}_{2}$ devido ao menor consumo de cimento, além de reduzir os custos de produção do concreto até $17 \%$. Outros pesquisadores, como ERGÜN [14], RANA et al. [15] e SINGH et al. [16], também têm investigado e demonstrado a viabilidade do uso do RBRO como substituto parcial ao cimento Portland na produção de concretos. Esses estudos, no entanto, majoritariamente se concentram na avaliação da resistência mecânica e na análise da redução de impactos ambientais.

Embora existam estudos $[17,18]$ que avaliam a influência da utilização do RBRO em propriedades relacionadas à durabilidade do concreto, DIETRICH et al. [19] destacam que a durabilidade de concretos contendo RBRO frente à ação de cloretos ainda necessita ser melhor compreendida. Ademais, em muitos casos o resíduo é utilizado em substituição aos agregados ou como adição à mistura. Neste cenário, este trabalho apresenta uma avaliação experimental de propriedades relacionadas à penetração de cloretos em concretos produzidos com substituição parcial de cimento por RBRO nos teores de 5, 7,5 e $10 \%$. São avaliadas a resistência à compressão axial, a absorção de água por capilaridade, a absorção de água por imersão e a penetrabilidade de cloretos nos concretos quando expostos à solução salina e ao ambiente natural. 


\section{MATERIAIS E MÉTODOS}

\subsection{Materiais}

Para a produção dos concretos, foram utilizadas areia quartzosa de granulometria média, enquadrada na zona utilizável apresentada pela NBR 7211 [20], e brita $n^{\circ} 1$ de origem granítica. A caracterização física dos agregados é apresentada na Tabela 1.

Tabela 1: Características físicas dos agregados utilizados.

\begin{tabular}{l|l|l}
\hline PARÂMETRO & AGREGADO MIÚDO & AGREGADO GRAÚDO \\
\hline Módulo de finura & $2,84^{\mathrm{a}}$ & $4,69^{\mathrm{a}}$ \\
\hline Dimensão máxima característica $(\mathrm{mm})$ & $4,75^{\mathrm{a}}$ & $19,00^{\mathrm{a}}$ \\
\hline Massa específica $\left(\mathrm{g} / \mathrm{cm}^{3}\right)$ & $2,62^{\mathrm{b}}$ & $2,60^{\mathrm{c}}$ \\
\hline Massa unitária solta $\left(\mathrm{g} / \mathrm{cm}^{3}\right)$ & $1,55^{\mathrm{d}}$ & $1,41^{\mathrm{d}}$ \\
\hline${ }^{\mathrm{a}} \mathrm{NBR}$ NM 248 [21] ${ }^{\mathrm{b}} \mathrm{NBR}$ NM 52 [22] ${ }^{\mathrm{c}} \mathrm{NBR}$ NM 53 [23], ${ }^{\mathrm{d}} \mathrm{NBR}$ NM 45 [24].
\end{tabular}

Foi utilizado cimento Portland de alta resistência inicial CP V- ARI, de acordo com a NBR 16697 [25], cuja massa específica é de $3,11 \mathrm{~g} / \mathrm{cm}^{3}$. Esse cimento foi escolhido por ser o que contém o maior teor de clínquer Portland dentre os cimentos disponíveis no mercado e, dessa forma, facilitar o entendimento da atuação do RBRO no concreto.

Por sua vez, o RBRO, coletado na forma de lama, foi gerado por uma empresa de beneficiamento de rochas ornamentais localizada na cidade de Pelotas/RS. A coleta seguiu a prescrição da NBR 10007 [26] e foi realizada diretamente no tanque de decantação da empresa, sendo todo o material utilizado neste trabalho coletado no mesmo dia. Com o resíduo seco e homogeneizado, realizou-se um estudo experimental para identificar qual peneira da série normal seria capaz de reter a granalha presente no RBRO. Através de inspeção visual, observou-se que utilização da peneira de $1,18 \mathrm{~mm}$ apresentava resultados satisfatórios. Assim, todo o resíduo foi peneirado em malha com abertura de $1,18 \mathrm{~mm}$ para retirada de granalha de aço e destorroamento, sendo eliminada, portanto, a necessidade de moagem. Após destorroado, o RBRO foi ainda passado em peneira com abertura de $300 \mu \mathrm{m}$ e, assim, considerado pronto para uso.

A granulometria do RBRO após o peneiramento foi avaliada utilizando um granulômetro a laser. A composição granulométria do resíduo é apresentada na Figura 1. Salienta-se que o material apresenta diâmetro médio das partículas $\left(\mathrm{D}_{50} \mathrm{D}_{50}\right)$ de $21,91 \mu \mathrm{m}$. Já os valores de $\mathrm{D}_{10} \mathrm{D}_{10}$ e $\mathrm{D}_{90} \mathrm{D}_{90}$ são, respectivamente, iguais a 3,66 e 71,09 $\mu \mathrm{m}$.

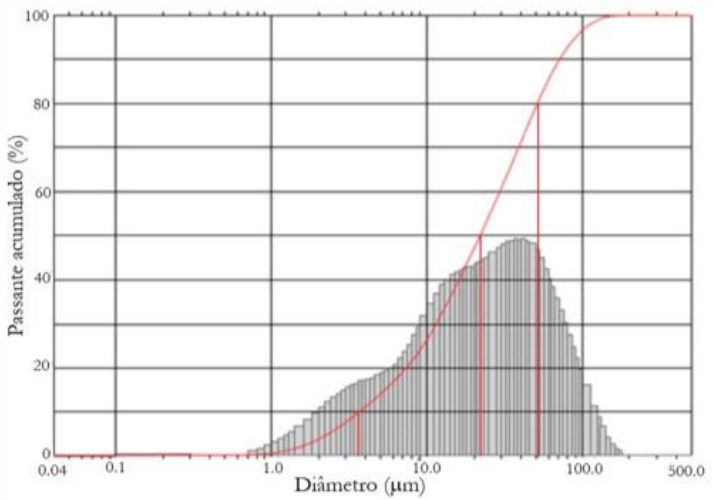

Figura 1: Composição granulométrica do resíduo utilizado.

Foram também determinadas a massa unitária [24] e a massa específica [27] do resíduo. Os resultados obtidos foram de $1,16 \mathrm{~g} / \mathrm{cm}^{3}$ e $2,64 \mathrm{~g} / \mathrm{cm}^{3}$, respectivamente.

A composição química do resíduo foi avaliada por meio da técnica de fluorescência de raios $\mathrm{X}$ por dispersão de energia (EDX). A Tabela 2 apresenta os resultados obtidos. Deve-se atentar ao fato de que, no material analisado, a soma dos óxidos $\mathrm{SiO}_{2}, \mathrm{Al}_{2} \mathrm{O}_{3}$ e $\mathrm{Fe}_{2} \mathrm{O}_{3}$ resulta em 62,42\%, valor inferior aos $70 \%$ indicados NBR 12653 [28] como mínimo para que um material seja considerado pozolânico. Além disso, obser- 
va-se que o teor de $\mathrm{K}_{2} \mathrm{O}$ presente no $\mathrm{RBRO}$ utilizado é significativamente superior ao relatado por outros autores [15, 17-19].

Por fim, para identificar a presença de elementos cristalinos na composição do RBRO, o resíduo foi submetido à análise de difração de raios $\mathrm{X}(\mathrm{DRX})$. Foi utilizado um difratômetro operando com radiação de $\mathrm{CuK} \alpha(=1,5418 \AA$ ) e monocromador de grafite, a uma tensão de $40 \mathrm{kV}$ e corrente de $30 \mathrm{~mA}$, varredura entre 5 e $80^{\circ}$ e velocidade angular de $2 \%$ min. A Figura 2 apresenta difratograma do resíduo.

Tabela 2: Composição química do RBRO utilizado.

\begin{tabular}{l|l|l|l|l|l|l|l|l|l|l|l|l}
\hline ELEMENTO & $\mathrm{SiO}_{2}$ & $\mathrm{~K}_{2} \mathrm{O}$ & $\mathrm{Al}_{2} \mathrm{O}_{3}$ & $\mathrm{Fe}_{2} \mathrm{O}_{3}$ & $\mathrm{CaO}$ & $\mathrm{TiO}_{2}$ & $\mathrm{MnO}$ & $\mathrm{ZnO}$ & $\mathrm{ZrO}_{2}$ & $\mathrm{SrO}$ & $\mathrm{CuO}$ & Outros \\
\hline TEOR (\%) & 34,085 & 20,287 & 18,770 & 12,570 & 12,181 & 1,444 & 0,178 & 0,122 & 0,118 & 0,103 & 0,101 & 0,0300 \\
\hline
\end{tabular}

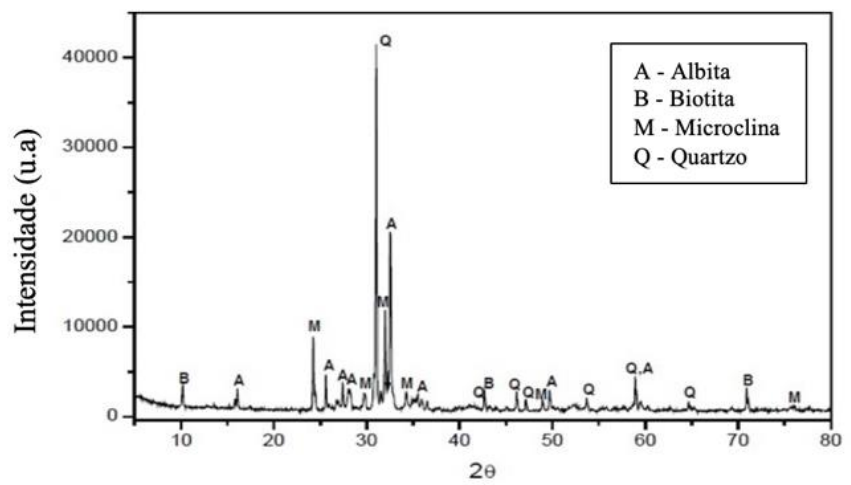

Figura 2: Difratograma de raios X obtido para a amostra de RBRO.

Com base na Figura 2, verifica-se que o RBRO é constituído principalmente por Quartzo e Albita. Podem ser observados ainda picos menos intensos de Microclina e Biotita. Visto que o material apresenta um pico cristalino referente ao Quartzo $\left(\mathrm{SiO}_{2}\right)$ bem definido e há ausência de halo amorfo, nota-se que este é um material não-pozolânico, corroborando com a análise realizada a partir dos resultados de EDX. Assim, ao utilizar o RBRO na mistura do concreto de cimento Portland, sua principal atuação será como filler, gerando diversos pontos de nucleação para a precipitação dos produtos de hidratação, tornando a pasta mais homogênea.

\subsection{Dosagem, produção e cura dos concretos}

A dosagem dos concretos foi realizada utilizando a metodologia apresentada pelo IPT/EPUSP [29]. Definiuse o teor ideal de argamassa seca em $51 \%(\alpha=0,51)$ e a relação água/aglomerante (ag/agl) de 0,60 foi adotada para todos os traços. Destaca-se que este valor de relação ag/agl $(0,60)$ é limite máximo normatizado pela NBR 6118 [30] para concretos expostos à Classe de Agressividade Ambiental (CAA) II. Foi produzido um traço de referência (REF), sem utilização do RBRO, e outros três com substituição parcial de cimento por RBRO nos teores de 5, 7,5 e $10 \%$ (denominados RBRO-5, RBRO-7,5 e RBRO-10, respectivamente). Uma vez que as massas específicas do cimento $\left(=3,11 \mathrm{~g} / \mathrm{cm}^{3}\right)$ e do $\operatorname{RBRO}\left(=2,64 \mathrm{~g} / \mathrm{cm}^{3}\right)$ são significativamente diferentes, a substituição foi realizada em massa com compensação de volume. A Tabela 3 apresenta o consumo de material em cada concreto.

A moldagem e a cura dos corpos de prova seguiram a prescrição da NBR 5738 [31]. Foram moldados corpos de prova cilíndricos com dimensões $\phi 100 \mathrm{~mm}$ x $200 \mathrm{~mm}$. Após desformados, estes foram submetidos à cura submersa até a realização dos ensaios propostos. 
Tabela 3: Consumo de material dos concretos avaliados (em kg/ $\mathrm{m}^{3}$ de concreto).

\begin{tabular}{l|l|l|l|l|l}
\hline CONCRETO & RELAÇÃO AG/AGL & CIMENTO & RBRO & AGREGADO MIÚDO & AGREGADO GRAÚDO \\
\hline REF & 0,60 & 360,00 & 0,00 & 864,00 & 1180,8 \\
\hline RBRO-5 & 0,60 & 342,00 & 15,28 & 864,00 & 1180,8 \\
\hline RBRO-7,5 & 0,60 & 333,00 & 22,92 & 864,00 & 1180,8 \\
\hline RBRO-10 & 0,60 & 324,00 & 30,56 & 864,00 & 1180,8 \\
\hline
\end{tabular}

\subsection{Resistência à compressão axial}

A resistência à compressão axial dos concretos foi avaliada por se tratar de uma propriedade mecânica que indica, de modo geral, a qualidade e a conformidade do material. Além disso, a resistência à compressão é tomada como parâmetro relacionado à durabilidade em normas que utilizam a metodologia prescritiva, caso da NBR 6118 [30]. O procedimento realizado seguiu o prescrito pela NBR 5739 [32]. A avaliação da resistência à compressão foi realizada nas idades de 3, 7 e 28 dias, sendo avaliados, a cada idade, cinco corpos de prova para cada traço.

\subsection{Absorção de água por capilaridade e absorção de água por imersão}

Os ensaios de absorção de água por capilaridade e de absorção de água por imersão estão bastante relacionados aos mecanismos de transporte do concreto. A partir do ensaio de absorção por capilaridade são obtidos dados relacionáveis à permeabilidade do concreto. A absorção por imersão, por sua vez, pode ser relacionada à porosidade do concreto [33]. A análise da absorção de água por capilaridade foi realizada de acordo com a NBR 9779 [34], enquanto o ensaio de absorção de água por imersão seguiu o prescrito pela NBR 9778 [35]. Ambos os ensaios foram realizados à idade de 28 dias e foram utilizados três corpos de prova de cada traço. Por fim, as amostras submetidas ao ensaio de absorção de água por capilaridade foram rompidas diametralmente e verificou-se a altura de ascensão capilar utilizando um paquímetro digital. Dessa forma, é possível calcular de maneira aproximada o raio médio dos capilares do concreto através da Equação 1 [36].

$$
\mathrm{h} \cong 120 \sqrt{\mathrm{tr} h} \cong 120 \sqrt{\mathrm{tr}}
$$

$\mathrm{Na}$ Equação 1, hh é a altura de ascensão de água no corpo de prova de concreto, tt é o tempo durante o qual o corpo de prova esteve em contato com a água e rr é o raio médio dos capilares.

\subsection{Penetrabilidade de cloretos}

A penetração de cloretos nos concretos foi avaliada em ambiente de laboratório e em ambiente natural. Quando avaliados em laboratório, os corpos de prova foram imersos parcialmente em solução salina. A solução de cloretos foi produzida a partir da dissolução de cloreto de sódio $(\mathrm{NaCl})$ em água a uma concentração de 3,5\%, valor também adotado por outros autores como PAGE et al. [37] e VIEIRA [38] e simulando, portanto, a salinidade total média dos oceanos. Salienta-se que outros autores [39, 40] também utilizaram essa metodologia para avaliar a penetração de cloretos em concretos. Durante o ensaio, o nível da solução foi mantido constante à altura de $1 / 3$ da altura dos corpos de prova. A penetração de cloretos foi avaliada quando decorridos 6 meses de exposição. A Figura 3 mostra os corpos de prova durante a imersão.

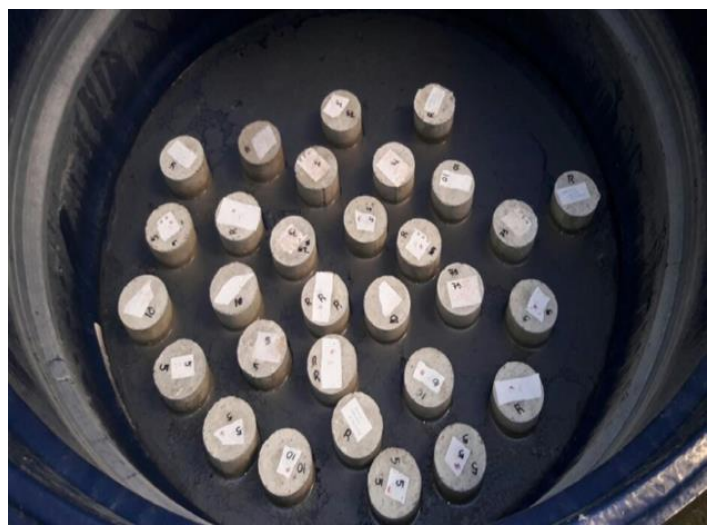

Figura 3: Imersão dos corpos de prova em solução salina. 
Além da avaliação da penetração de cloretos nos concretos imersos em solução salina, avaliou-se também o ingresso desses íons em concretos expostos ao ambiente natural. Para isso, amostras foram dispostas nas cidades de Pelotas/RS e Rio Grande/RS. Nestes casos a avaliação da penetração de cloretos foi realizada após 6 e 12 meses de exposição.

A cidade de Pelotas/RS encontra-se afastada aproximadamente $60 \mathrm{~km}$ do mar e está localizada às margens do canal São Gonçalo, que liga as lagoas Mirim e dos Patos. Assim, as amostras estiveram expostas a um ambiente urbano com umidade relativa anual média superior a $80 \%$ e protegidas parcialmente das ações do ambiente por uma laje. Os corpos de prova foram expostos no bairro Porto, zona sul da cidade, a cerca de $50 \mathrm{~m}$ da margem do canal São Gonçalo. A Figura 4 apresenta as condições de exposição na cidade de Pelotas/RS.

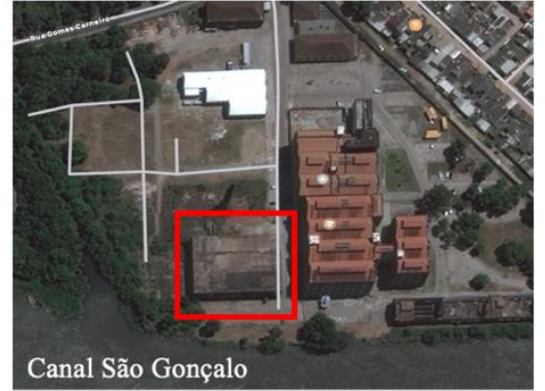

(a)

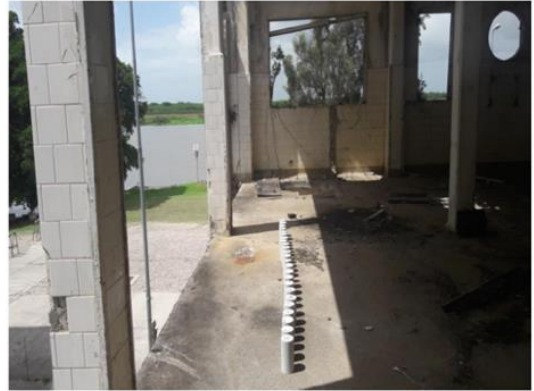

(b)

Figura 4: (a) Localização do ambiente de exposição na cidade de Pelotas/RS (Fonte: Apple Mapas, 2020), (b) Disposição das amostras para exposição.

A cidade de Rio Grande, por sua vez, é banhada pelo Oceano Atlântico. Os concretos foram dispostos no bairro Carreiros, distante 1,2 km do Porto de Rio Grande, expostos ao ar livre sobre uma marquise, como mostra a Figura 5.

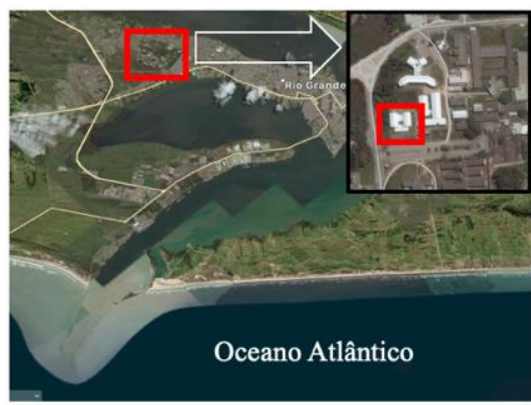

(a)

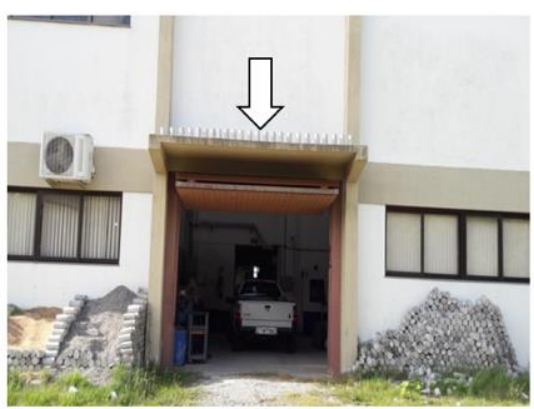

(b)

Figura 5: (a) Localização do ambiente de exposição na cidade de Rio Grande/RS (Fonte: Apple Mapas, 2020), (b) Disposição das amostras para exposição.

Na Tabela 4 são apresentados valores das variáveis climáticas temperatura média, umidade relativa e precipitação acumulada observadas durante o período de exposição dos concretos ao ambiente natural. Salienta-se que os dados apresentados na Tabela 4 foram obtidos junto à Estação Agroclimatológica de Pelotas e ao Instituto Nacional de Meteorologia.

Tabela 4: Variáveis climáticas observadas durante a exposição dos concretos em ambiente natural.

\begin{tabular}{l|c|c|c|c}
\hline CIDADE & PERÍODO & TEMPERATURA MÉDIA (으) & UMIDADE RELATIVA (\%) & $\begin{array}{c}\text { PRECIPITAÇÃO ACU- } \\
\text { MULADA (MM) }\end{array}$ \\
\hline \multirow{2}{*}{ Pelotas/RS } & $1^{\circ}$ ao $6^{\circ}$ mês & 18,85 & 85,12 & 652,80 \\
\cline { 2 - 5 } & $7^{\circ}$ ao $12^{\circ}$ mês & 18,99 & 82,47 & 864,40 \\
\hline \multirow{2}{*}{ Rio Grande/RS } & $1^{\circ}$ ao $6^{\circ}$ mês & 18,98 & 73,08 & 417,80 \\
\cline { 2 - 5 } & $7^{\circ}$ ao $12^{\circ}$ mês & 15,59 & 76,44 & 858,20 \\
\hline
\end{tabular}


Ao completarem as idades de 6 meses - para os concretos submetidos à imersão parcial, e 6 e 12 meses - para as amostras expostas ao ambiente natural, a profundidade de penetração de cloretos foi avaliada. Para isso, os corpos de prova foram rompidos diametralmente e, após, submetidos à aspersão de solução de nitrato de prata $\left(\mathrm{AgNO}_{3}\right)$ a $0,10 \mathrm{~N}$ em água deionizada. Para a determinação da profundidade média de penetração dos íons foram avaliadas quatro amostras de cada traço, sendo, em cada corpo de prova, realizadas sete medições, como indicado pela NT Build 492 [41]. As medições foram realizadas utilizando registro fotográfico realizado após a aspersão de $\mathrm{AgNO}_{3}$ e com auxílio do software AutoCad®.

\section{RESULTADOS}

\subsection{Resistência à compressão axial}

Os resultados obtidos no ensaio de resistência à compressão axial são apresentados na Figura 6.

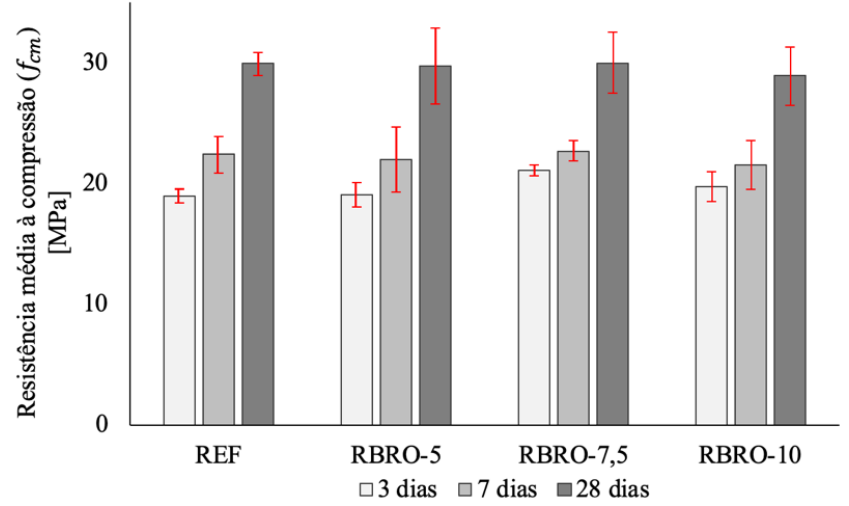

Figura 6: Resistência média à compressão dos concretos avaliados.

Com base na Figura 6, verifica-se que, à idade de 3 dias, todos os traços com utilização de RBRO possuem resistência média à compressão $\left(\mathrm{f}_{\mathrm{cm}} \mathrm{f}_{\mathrm{cm}}\right)$ superior ao concreto referência, demonstrando a atuação física do resíduo, uma vez que, neste momento, muitas das reações de hidratação do cimento ainda estão ocorrendo.

Já quando avaliadas as resistências obtidas aos 28 dias, nota-se que o traço RBRO-7,5 apresentou o melhor desempenho. Ao avaliar resistência à compressão do concreto aos 28 dias, ERGUN [14] também obteve resultados superiores quando utilizado o resíduo no teor de 7,5\%. Além disso, apesar de o concreto RBRO-10 ser o que apresentou maior redução de $\mathrm{f}_{\mathrm{cm}} \mathrm{f}_{\mathrm{cm}}$ em relação ao traço referência, essa variação $(=$ $3,37 \%$ ) é bastante pequena quando analisada a precisão do ensaio em questão. Dessa forma, em termos práticos, do ponto de vista da resistência mecânica, o teor de substituição mostra-se indiferente, sendo a substituição de cimento por RBRO, neste caso, justificada somente por questões de reaproveitamento de resíduos.

Visando avaliar a significância estatística das variáveis "teor de substituição" e "idade", realizou-se o teste de Análise de Variância (ANOVA) com nível de significância $\alpha \alpha=0,05$. Quando analisadas separadamente, verificou-se que ambas as variáveis possuem efeito significativo sobre a resistência à compressão axial dos concretos. Entretanto, não há influência significativa entre o "teor de substituição" e a "idade". Essa inexistência de interação demonstra que a substituição de cimento por RBRO não provoca variações significativas ao longo do tempo. Esse comportamento já era esperado visto que o resíduo não possui atividade pozolânica. Por fim, ao realizar o Teste Tukey, observou-se que os resultados obtidos não são estatisticamente diferentes em nenhuma das idades em que a resistência à compressão foi avaliada.

\subsection{Absorção de água por capilaridade e absorção de água por imersão}

A Figura 7 apresenta os resultados obtidos no ensaio de absorção de água por capilaridade. Inicialmente notase que cada teor propiciou um comportamento diferente aos concretos, não havendo uma direta proporcionalidade entre o teor de resíduo utilizado e o aumento de massa dos corpos de prova devido à absorção capilar. Enquanto os traços REF e RBRO-5 apresentaram absorção por capilaridade muito similar durante todo o ensaio, com pequenas variações observadas somente nas últimas medições, a mistura RBRO-7,5 foi a que apresentou melhor desempenho, reduzindo a absorção capilar em 12,61 \% frente ao traço referência ao final do ensaio. 
O concreto RBRO-10, no entanto, foi o que apresentou pior desempenho, com absorção $12,62 \%$ superior à mistura REF, demonstrando a preponderância do efeito cimentante em relação ao efeito filler e corroborando com o apresentado por autores como BACARJI et al. [6], que apontam que a utilização do resíduo de beneficiamento de rochas ornamentais pode apresentar resultados negativos com relação aos mecanismos de transporte do concreto quando em teores iguais ou superiores a $10 \%$.

Através do teste ANOVA, constatou-se a significância estatística da variável "teor de substituição" na absorção capilar dos concretos. Quando realizado o Teste Tukey, verificou-se que o traço RBRO-10 pode ser considerado estatisticamente diferente do concreto referência. Por outro lado, a absorção de água dos concretos com 5 e 7,5\% de substituição de cimento por RBRO é estatisticamente igual ao traço REF quando considerado um intervalo de confiança de $95 \%$.

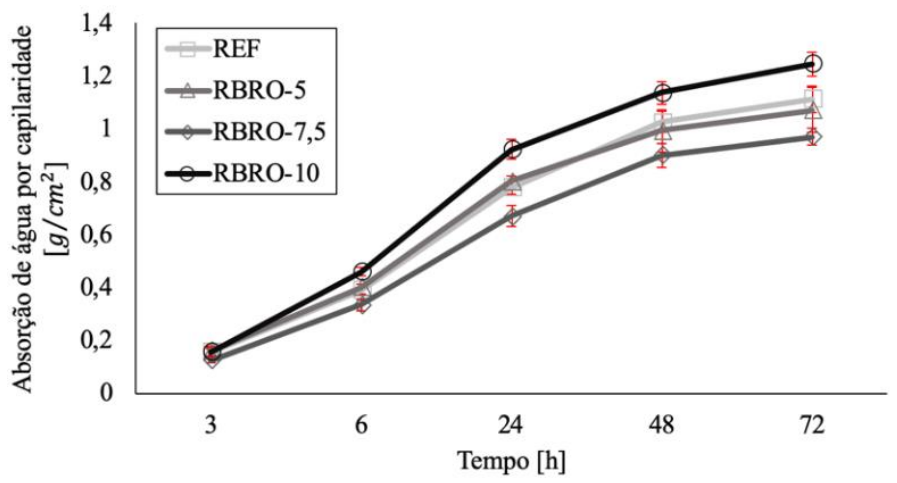

Figura 7: Absorção de água por capilaridade dos traços investigados.

As alturas de ascensão capilar medidas imediatamente após o fim do ensaio de absorção de água por capilaridade e os raios médios dos capilares dos concretos, calculados de acordo com a Equação 1, são apresentados na Tabela 5 .

Tabela 5: Alturas de ascensão capilar e raio médio dos capilares dos concretos.

\begin{tabular}{l|c|c}
\hline CONCRETO & $\begin{array}{c}\text { ALTURA DE ASCENSÃO CAPILAR }(\mu \pm \sigma \mu \pm \\
\sigma)(\mathbf{c m})\end{array}$ & RAIO MÉDIO DOS CAPILARES (cm) \\
\hline REF & $5,50 \pm \pm 0,319$ & $8,10 \mathrm{E}-09$ \\
\hline RBRO-5 & $5,00 \pm \pm 0,315$ & $6,70 \mathrm{E}-09$ \\
\hline RBRO-7,5 & $5,20 \pm \pm 0,224$ & $7,24 \mathrm{E}-09$ \\
\hline RBRO-10 & $8,00 \pm \pm 0,304$ & $1,71 \mathrm{E}-08$ \\
\hline
\end{tabular}

Nota: $\mu \mu=$ média; $\sigma \sigma=$ desvio padrão.

Verifica-se, com base na Tabela 5, que os traços REF, RBRO-5 e RBRO-7,5 apresentam a mesma ordem de grandeza quando analisadas a altura de ascensão capilar e o raio médio dos capilares. $\mathrm{O}$ concreto RBRO-10, por sua vez, apresenta valores consideravelmente superiores, indicando um maior potencial de entrada de agentes agressivos no concreto.

Na Figura 8 são apresentados os resultados de absorção de água por imersão e de índice de vazios. A análise desses dois parâmetros pode ser realizada em conjunto, visto que estão diretamente ligados e possuem alta correlação, com $\mathrm{R}^{2}=0,96$. 


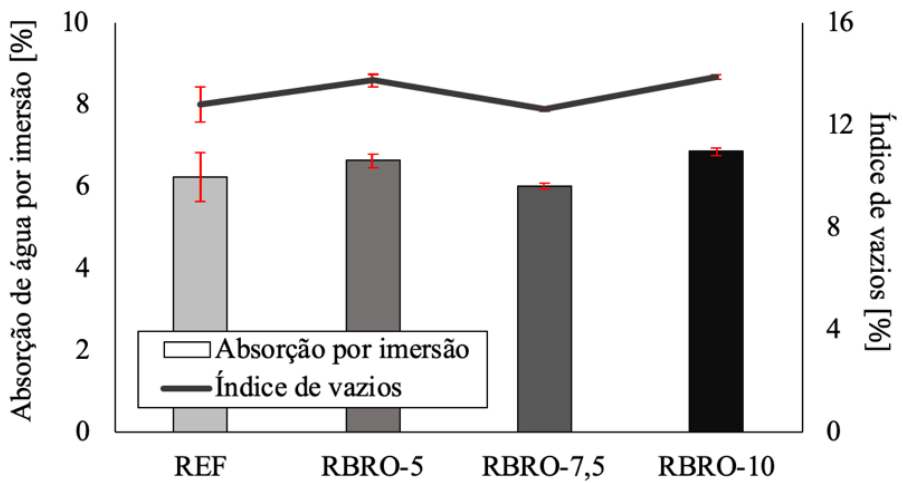

Figura 8: Influência do RBRO na absorção por imersão e índice de vazios dos concretos.

Observa-se que a utilização do RBRO no teor de 7,5\% foi novamente a que apresentou resultados mais satisfatórios, reduzindo a porosidade aberta dos concretos e, consequentemente, sua absorção. Quando realizado o teste de Análise de Variância, novamente foi verificada a significância estatística da variável "teor de substituição". No entanto, diferentemente do resultado obtido para a absorção de água por capilaridade, através do Teste Tukey identificou-se que todos os traços com utilização do resíduo apresentam similaridade com o concreto referência, indicando a possibilidade de substituição de até $10 \%$ do cimento Portland por RBRO sem que hajam variações estatisticamente significativas na absorção por imersão e no índice de vazios.

\subsection{Penetrabilidade de cloretos}

As profundidades médias de penetração de cloretos obtidas nos concretos expostos à imersão parcial em solução salina por 6 meses são apresentadas na Figura 9.

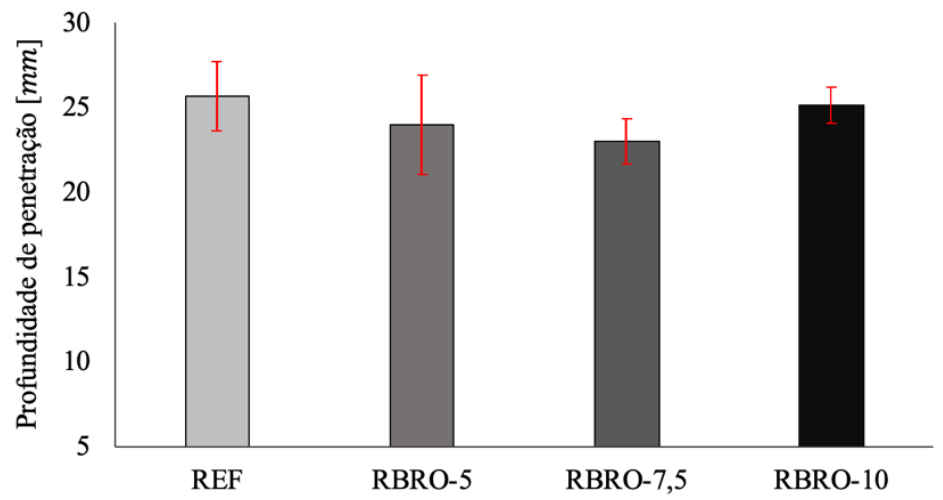

Figura 9: Profundidade de penetração de cloretos e coeficiente de penetração dos concretos avaliados em laboratório.

Verifica-se que o uso do RBRO propiciou leves reduções na penetrabilidade de cloretos nos concretos. Este fato está ligado ao efeito filler proporcionado pelas finas partículas do RBRO, bem como ao $\mathrm{Al}_{2} \mathrm{O}_{3}$ presente na composição do resíduo, que, ao combinar-se com os cloretos conduz à formação de sal de Friedel (cloroaluminato), fixando os íons e reduzindo sua penetração. Destaca-se novamente que, ainda que tenha reduzido ligeiramente a penetração de cloretos em relação ao concreto referência, o traço RBRO-10 apresentou o pior desempenho dentre as misturas com utilização do resíduo.

Quando realizado o teste ANOVA verificou-se que variável "teor de substituição" não exerceu influência significativa nos resultados dessa propriedade, ou seja, ao substituir até $10 \%$ de cimento Portland por RBRO, a penetrabilidade de cloretos nos concretos não sofreu alterações estatisticamente significativas.

Na Figura 10 são apresentados os valores médios de penetração de cloretos dos concretos expostos ao ambiente natural nas cidades de Pelotas/RS e Rio Grande/RS por períodos de 6 e 12 meses. Ao analisar os dados apresentados na Figura 10, deve-se atentar ao fato de que os valores apresentados são substancialmente inferiores aos obtidos em laboratório, fato que está relacionado à elevada concentração salina utilizada no ensaio de imersão parcial. 


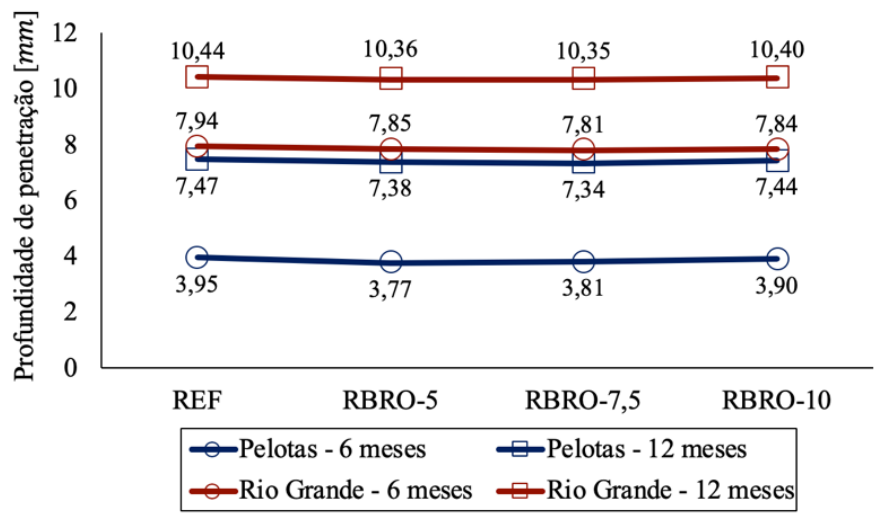

Figura 10: Profundidade de penetração de cloretos e coeficiente de penetração dos concretos expostos ao ambiente natural.

Como esperado, observa-se que novamente o traço REF apresentou a maior penetrabilidade entre os concretos avaliados, tanto aos 6 quanto aos 12 meses em ambos os locais de exposição natural. Como já discutido anteriormente, esse comportamento está relacionado ao refinamento dos poros capilares do concreto proporcionado pelo RBRO, aumentando a tortuosidade destes e elevando a compacidade da matriz cimentícia, e à possível fixação dos íons cloro ao se combinarem com a alumina $\left(\mathrm{Al}_{2} \mathrm{O}_{3}\right)$ disponível no resíduo.

Os valores visivelmente menores apresentados pelos concretos expostos na cidade de Pelotas/RS ocorrem devido ao fato dessa não ser uma cidade próxima ao mar. SOUZA [42], no entanto, aponta que em períodos de baixa precipitação foram identificados teores significativos de íons cloreto em pontos entre as lagoas Mirim e dos Patos.

Ao realizar o teste de Análise de Variância, a influência das variáveis "teor de substituição", "tempo de exposição" e "local de exposição" na penetração de cloretos foi avaliada. Quando considerado somente o "teor de substituição", confirmou-se novamente que o teor de substituição de cimento por RBRO não exerceu influência estatisticamente significativa na penetração de cloretos. Ao analisar somente a variável independente "tempo de exposição", a análise demonstrou que este fator gera diferenças significativas entre as médias das profundidades de penetração de cloretos. Por fim, quando considerada a influência do "local de exposição", o teste ANOVA indica que há diferença significativa entre as médias das profundidades de penetração de cloretos devido à variação do local de exposição.

\section{CONCLUSÕES}

Neste trabalho foram avaliadas propriedades relacionadas à penetração de cloretos em concretos produzidos com substituição parcial de cimento Portland por resíduo de beneficiamento de rochas ornamentais. Destacase que para que o RBRO seja utilizável como substituto do cimento, é necessária uma preparação prévia do material, a fim de que se atinjam dimensões aceitáveis. Deve-se atentar ao fato de que os concretos avaliados neste trabalho seguem as prescrições referentes à CAA II da NBR 6118 [30]. Além disso, outros aspectos que influenciam na durabilidade de estruturas de concreto armado, como, dentre outros, o coeficiente de difusão de cloretos, a resistência ao ingresso de $\mathrm{CO}_{2}$ e a resistividade elétrica de concretos contendo RBRO, necessitam ainda ser avaliados. Ademais, destacam-se como principais conclusões:

a) À idade de 28 dias somente o traço RBRO-7,5 apresentou resistência à compressão superior à mistura referência. No entanto, as diferenças apresentadas pelos concretos RBRO-5 e RBRO-10 em relação ao traço REF não são superiores a 1,01 MPa, sendo essa diferença bastante pequena quando analisado o nível de precisão do ensaio em questão;

b) Quanto à absorção de água por capilaridade, a utilização do RBRO proporcionou uma redução da taxa de absorção para os teores de substituição de até 7,5\%. Esse decréscimo nos valores de absorção de água para teores de até 7,5\%, também identificado por outros autores [12], indica um provável teor ótimo de RBRO para sua atuação como filler no concreto;

c) De semelhante modo, o traço RBRO-7,5 apresentou os melhores resultados quanto avaliados a absorção por imersão e o índice de vazios. A análise estatística demonstrou, no entanto, que o teor de substituição não gerou variações estatisticamente significativas nessa propriedade;

d) Quando avaliada a penetrabilidade de cloretos em laboratório e em ambiente natural, novamente não foram identificadas variações estatisticamente significativas geradas pelos diferentes teores de substitui- 
ção de cimento por RBRO. Ainda assim, o traço RBRO-7,5 apresentou a menor penetração de íons cloreto, sendo este resultado condizente com o observado nos ensaios de absorção por capilaridade e por imersão;

e) A substituição parcial de até $7,5 \%$ de cimento por RBRO conduziu a um material que apresenta comportamento similar ao concreto referência em propriedades como resistência mecânica à compressão, absorção de água e penetrabilidade de cloretos, proporcionando um uso sustentável a um resíduo que seria descartado no meio ambiente e possibilitando a redução do consumo de cimento no concreto. O concreto RBRO-10, por sua vez, ainda que tenha apresentado resultados da mesma ordem de grandeza dos demais concretos quando avaliada a resistência à compressão, apresentou prejuízos quando analisadas as propriedades relacionadas à durabilidade.

\section{AGRADECIMENTOS}

O presente trabalho foi realizado com apoio da Coordenação de Aperfeiçoamento de Pessoal de Nível Superior - Brasil (CAPES) - Código de Financiamento 001.

\section{BIBLIOGRAFIA}

[1] BEUSHAUSEN, H., LUCO, L.F., Performance-Based Specifications and Control of Concrete Durability - State-of-the-Art Report RILEM TC 230-PSC, 1 ed., New York, Springer, 2016.

[2] CAO, Y., GEHLEN, C., ANGST, U., et al., "Critical chloride content in reinforced concrete - An update review considering Chinese experience", Cement and Concrete Research, v. 117, pp. 58-68, Mar. 2019.

[3] WALLY, G.B., MAGALHÃES, F.C., SILVA FILHO, L.C.P., "Conceitos e aspectos da abordagem com base no desempenho na avaliação da durabilidade de estruturas de concreto armado expostas a ambientes agressivos", Revista Concreto \& Construções, v. 100, pp. 81-85, Dec. 2020.

[4] OLLIVIER, J.P., TORRENTI, J.M., "A estrutura porosa dos concretos e as propriedades de transporte", In: Ollivier, J.P., Vichot, A. (eds), Durabilidade do concreto - Bases científicas para a formulação de concretos duráveis de acordo com o ambiente, Trad.: Cascudo, O., Carasek, H., São Paulo, Brasil, Instituto Brasileiro do Concreto, 2014.

[5] WALLY, G.B., MAGALHÃES, F.C., SELL JUNIOR, F.K., et al., "Estimating service life of reinforced concrete structures with binders containing silica fume and metakaolin under chloride environment: durability indicators and probabilistic assessment", Materials and Structures, v. 54, n. 2, article 98, Apr. 2021.

[6] BACARJI, E., TOLEDO FILHO, R.D., KOENDERS, E.A.B., et al., "Sustainability perspective of marble and granite residues as concrete fillers", Construction and Building Materials, v. 45, pp. 1-10, Aug. 2013.

[7] GEIKER, M.R., MICHEL, A., STANG, H., et al., "Limit states for sustainable reinforced concrete structures", Cement and Concrete Research, v. 122, pp. 189-195, Aug. 2019.

[8] AREL, H.S., "Recyclability of waste marble in concrete production", Journal of Cleaner Production, v. 131, pp. 179-188, Sep. 2016.

[9] GARAS, G.L., ALLAM, M.E., BAKHOUM, E.S., "Studies undertaken to incorporate marble and granite wastes in green concrete production", ARPN Journal of Engineering and Applied Sciences, v. 9, n. 9, pp. 1559-1564, Sep. 2014.

[10] ASSOCIAÇÃO BRASILEIRA DE ROCHAS ORNAMENTAIS (ABIROCHAS). "O setor de rochas ornamentais e de revestimento", Informe 2017, São Paulo, Brasil, ABIROCHAS, 2017.

[11] MITTRI, S.H.M., DEGEN, M.K., VIEIRA, G.L., et al., "Assessment of the pozzolanic activity of ornamental stone waste after heat treatment and its effect on the mechanical properties of concretes", Revista IBRACON de Estruturas e Materiais, v. 11, n. 6, pp. 1186-1207, Dec. 2018.

[12] GHORBANI, S., TAJI, I., DE BRITO, J., et al., "Mechanical and durability behavior of concrete with granite waste dust as partial replacement under adverse exposure conditions", Construction and Building Materials, v. 194, pp. 143-152, Jan. 2019.

[13] SOLIMAN, N.M., "Effect of using Marble Powder in Concrete Mixes on the Behavior and Strength of R.C. Slabs", International Journal of Current Engineering and Technology, v. 3, n. 5, pp. 1863-1870, Dec. 2013.

[14] ERGÜN, A., "Effects of the usage of diatomite and waste marble powder as partial replacement of cement on the mechanical properties of concrete", Construction and Building Materials, v. 11, n. 2, pp. 806812, Feb. 2011. 
[15] RANA, A., KALLA, P., CSETENYI, L.J., "Sustainable use of marble slurry in concrete", Journal of Cleaner Production, v. 94, pp. 304-311, May 2015.

[16] SINGH, M., SRIVASTAVA, A., BHUNIA, D., “An investigation on effect of partial replacement of cement by waste marble slurry", Construction and Building Materials, v. 134, pp. 471-488, Mar. 2017.

[17] BINICI, H., SHAH, T., AKSOGAN, O., et al., "Durability of concrete made with granite and marble as recycle aggregates”, Journal of Materials Processing Technology, v. 208, n. 1-3, pp. 299-308, Nov. 2008.

[18] VIJAYALAKSHMI, M., SEKAR, A.S.S., GANESH PRABHU, G., "Strength and durability properties of concrete made with granite industry waste", Construction and Building Materials, v. 46, pp. 1-7,

Sep. 2013.

[19] DIETRICH, Y.P., TELES, C.R., VIEIRA, G.L., "Desempenho mecânico e análise da corrosão das armaduras em concretos produzidos com adição de resíduos de rochas ornamentais", Revista Matéria, v. 22, n. 4, e-11891, 2017.

[20] ASSOCIAÇÃO BRASILEIRA DE NORMAS TÉCNICAS, NBR 7211: Agregados para concreto - Especificações. Rio de Janeiro, 2009.

[21] ASSOCIAÇÃO BRASILEIRA DE NORMAS TÉCNICAS, NBR NM 248: Agregados - Determinação da composição granulométrica. Rio de Janeiro, 2003.

[22] ASSOCIAÇÃO BRASILEIRA DE NORMAS TÉCNICAS, NBR NM 52: Agregado miúdo - Determinação da massa específica e massa específica aparente. Rio de Janeiro, 2009.

[23] ASSOCIAÇÃO BRASILEIRA DE NORMAS TÉCNICAS, NBR NM 53: Agregado graúdo - Determinação da massa específica, massa específica aparente e absorção de água. Rio de Janeiro, 2009.

[24] ASSOCIAÇÃO BRASILEIRA DE NORMAS TÉCNICAS, NBR NM 45: Agregados - Determinação da massa unitária e do volume de vazios. Rio de Janeiro, 2006.

[25] ASSOCIAÇÃO BRASILEIRA DE NORMAS TÉCNICAS, NBR 16697: Cimento Portland - Requisitos. Rio de Janeiro, 2018.

[26] ASSOCIAÇÃO BRASILEIRA DE NORMAS TÉCNICAS, NBR 10007: Amostragem de resíduos sólidos. Rio de Janeiro, 2004.

[27] ASSOCIAÇÃO BRASILEIRA DE NORMAS TÉCNICAS, NBR NM 23: Cimento Portland e outros materiais em pó - Determinação da específica. Rio de Janeiro, 2001.

[28] ASSOCIAÇÃO BRASILEIRA DE NORMAS TÉCNICAS, NBR 12653: Materiais pozolânicos - Requisitos. Rio de Janeiro, 2014.

[29] HELENE, P., TERZIAN, P., Manual de Dosagem e Controle do Concreto, São Paulo, Pini, 1993.

[30] ASSOCIAÇÃO BRASILEIRA DE NORMAS TÉCNICAS, NBR 6118: Projeto de estruturas de concreto - Procedimento. Rio de Janeiro, 2014.

[31] ASSOCIAÇÃO BRASILEIRA DE NORMAS TÉCNICAS, NBR 5738: Concreto - Procedimento para moldagem e cura de corpos de prova. Rio de Janeiro, 2015 (corrigida em 2016).

[32] ASSOCIAÇÃO BRASILEIRA DE NORMAS TÉCNICAS, NBR 5739: Concreto - Ensaio de compressão de corpos de prova cilíndricos. Rio de Janeiro, 2018.

[33] TEODORO, R., “Avaliação das características de diferentes metacaulins e sua influência na estrutura interna do concreto e em propriedades ligadas à durabilidade”, Dissertação de M.Sc., EECA/UFG, Goiânia, GO, Brasil, 2016.

[34] ASSOCIAÇÃO BRASILEIRA DE NORMAS TÉCNICAS, NBR 9779: Argamassa e concreto endurecidos - Determinação da absorção de água por capilaridade. Rio de Janeiro, 2012.

[35] ASSOCIAÇÃO BRASILEIRA DE NORMAS TÉCNICAS, NBR 9778: Argamassa e concreto endurecidos - Determinação da absorção de água, índice de vazios e massa específica. Rio de Janeiro, 2009.

[36] MENDES, M.V.A.S., “Avaliação das propriedades de transporte de massa em concretos contendo adições minerais”, Dissertação de M.Sc. EEC/UFG, Goiânia, GO, Brasil, 2009.

[37] PAGE, M.M., PAGE, C.L., NGALA, V.T., et al., "Ion chromatographic analysis of corrosion inhibitors in concrete", Construction and Building Materials, v. 16, n. 2, pp. 73-81, Mar. 2002.

[38] VIEIRA, F.M.P., "Contribuição ao estudo de corrosão das armaduras em concretos com adição de sílica ativa”, Tese de D.Sc., PPGEM/UFRGS, Porto Alegre, RS, Brasil, 2003. 
[39] ANTOLINI, M.B., "Retração total e penetração de cloretos em concretos compostos com cinza de lodo de ETA e outras adições minerais”, Dissertação de M.Sc., PPGEC/UFSM, Santa Maria, RS, Brasil, 2015.

[40] COLETTO, T., "Penetração de cloretos em concretos compostos com cinza de lodo de estação de tratamento de água em diferentes teores de adição", Dissertação de M.Sc., PPGEC/UFSM, Santa Maria, RS, Brasil, 2017.

[41] NORDTEST, NT Build 492: Concrete, mortar and cement-based repair materials - Chloride migration coefficient from non-steady-state migration experiments. Espoo, 1999.

[42] SOUZA, M.F., "Qualidade da água do canal São Gonçalo - RS/Brasil - Uma avaliação hidroquímica e considerando seus usos múltiplos”, Dissertação de M.Sc., PPGRH/UFPel, Pelotas, RS, Brasil, 2015.

\section{ORCID}

Fernando Ritiéle Teixeira

Gustavo Bosel Wally

Fábio Costa Magalhães

Félix Krolow Sell Junior

Charlei Marcelo Paliga

Ariela da Silva Torres https://orcid.org/0000-0001-8498-9263

https://orcid.org/0000-0003-3008-3815

https://orcid.org/0000-0001-8463-1501

https://orcid.org/0000-0002-6286-5371

https://orcid.org/0000-0003-0521-4764

https://orcid.org/0000-0003-4686-9759 